\title{
SEMIOTIC ANALYSIS ON SELECTED OPPO SMARTPHONE'S ADVERTISEMENTS
}

\author{
Eka Margianti Sagimin ${ }^{1}$ dan Anisa Linda Priyani ${ }^{2}$ \\ ${ }^{1,2}$ English Department, Universitas Pamulang, Tangerang Selatan, Banten \\ Email: ekamargy@yahoo.com ${ }^{1}$
}

\begin{abstract}
This study is attempted to explain and analyze the semiotic process and the messages implied on Oppo Smartphone's advertisment. The semiotic approach is used to identify and to analyze the data which focuses on Representament, Object and Interpretant by using Triadic Semiosis Concept of C.S. Pierce's theory. The objective of this study is to analyze how semiosis proses occurs and to interpret the messages conveyed by the sign in Oppo Smartphone's Advertisement. The study employed descriptive qualitative as the data were collected in the form of written words which produce the descriptive information. Based on the result finding, there are five advertisments of Oppo's selected advertisments; Oppo F1,F5,N1 Mini, R1 and R5. Those advertisments have hidden messages which make the viewers or customers unable to catch the messages properly. From the result analysis, it can be affirmed that all aspects in the advertisments have the same messages to persuade the readers to buy the product even though the sign in each advertisement is different.
\end{abstract}

Keyword: Semiotic, Representament, Object, Interpretant, Advertisments, Oppo's Smarthphone.

\section{INTRODUCTION}

Everyday people always do communication with others. In the process of communication, language is needed in order to make a communication runs smoothly. By using language, people are capable to share ideas, feelings, or experiences that are delivered from other people, individual, community, or group. Sobur (2004) points out, "Language is a tool to express ideas, feelings, or experiences and to communicate with other people". Hence, it proves that language has an essential role in human communication.

According to Griffith (2011), communication between sender and receiver is divided into two ways: direct and indirect communication. Direct communication is when two people or more do communication without any media. Meanwhile, indirect communication requires the participants to use media as an instrument to convey messages. For example, the company promotes the products to consumers through advertisements on television, radio, or social media.

Nowadays, in the globalization era the message is not only communicated directly by people but also by using media such as magazines, newspapers, posters, banner, and advertisement. Advertisement is one of media communication which is used by various company. The company communicates indirectly with their customers to deliver a message about products, ideas, or services. In order words, the advertisement can be a mediator of communication between sellers and buyers. 
At the present time, the advertisement has a great development. Nearly, many advertisements can be found anywhere. For instance, when people want to go somewhere they will see the advertising on the billboard all along the road. Indeed, when people watch television, usually advertisement appears on commercial break. Besides, when they read the newspaper or the magazine they will find advertisement easily. It can be said that the advertisements exist mostly in every human activity.

Since advertising can be found easily almost everywhere, there are many creators of advertisement race to be creative in producing an advertisement presented in unique and creative design in order to attract the consumer's attention. However, in an attractive design of advertisement, not all people can understand and catch the messages that contain in the advertisement. The viewers find the difficulties on interpreting the advertisement design.

In understanding the messages in advertisement completely, semiotic approach can be applied. The advertisement can be studied through semiotic approach because it consists of many signs. Semiotic is knowns as study about signs. In semiotic, there are many approaches to interpret signs, one of them is Charles Sanders Pierce's theory. Pierce asserted three important elements of signs which can be explained through Representament, Object, and Interpretant.

Related to the theory of semiotic above, the advertisements of Oppo smartphone were chosen as the objects in this study. Oppo is well known as brand of mobile electronic device around the world. According to information in Oppo smartphone official website, www.oppo.com, Oppo entered the mobile phone market in 2008. Now, it was growing fast in more than 20 countries worldwide. It has been standing out from other mobile phone companies because of its design, manufacturing capability, and rich feature sets of Oppo. At the same time, Oppo smartphone uses advertisement to promote their product. The advertisement can be found on TV, magazines, or accessed through internet. The design of advertisement has short text and supported by pictures, which are attractive and full of meanings. There is one example of Oppo advertisement. The advertisement appears with the picture of Indonesian singer named Isyana Saraswati who takes beautiful selfie after waking up in morning by using Oppo smartphone device with combining the text "F1 Selfie Expert". For several people at the first time seeing this advertisement might be confused about the message. They cannot understand directly the messages delivered by the advertisement creator.

Therefore, the study entitled "Semiotic Analysis on Selected Oppo Smartphone's Advertisements" tries to uncover the meaning of the sign in Oppo smartphone advertisements. The writer is interested in analyzing Oppo smartphone advertisements as the object in this study because those advertisements have creative designs and meaningful messages in every advertisement. However sometimes the viewers can not catch the message of the advertisement succesful. Hence, the writer would like to explore deeply the sign and uncover the real message by analyzing the semiosis process. In this study, semiotic approach of Pierce is used to examine the sign of each advertisement which is mostly constructed in the form of picture with combining simple text. 


\section{SEMIOTICS}

In linguistics, the word semiotic is derived from the Greek term, Semion, which means the interpretation of sign. Semiotic is always defined as a knowledge that concerns with the study of signs. Zoest (1992) states, "semiotic is study about sign and everything which relation with its, its function, relation with other sign, sender, receiver by the used the sign." As what has been mentioned, it can be concluded that semiotic is used to understand the signs and everything which relate with it such as the meaning and the function, especially in system of communication.

Besides, there is other broad definition about semiotic from Eco as cited in Chandler (2007): "Semiotic is concerned with everything that can be taken as a sign significantly substituting for someone else. This something else does not necessary substituting for something else. This something else not necessary have to exist or to actually be somewhere at the moment in which a sign stand in for it."

Based on Eco's statement, it can be confirmed that semiotic gives big attention to everything that can be esteemed as a sign. The sign includes words, images, sounds, gestures, acts, and objects. Semiotic involves the study of sign in anything not only refer to sign in everyday speech but also in everyday life. In human life, there are some signs that exist to inform something to other people. For instance, a wave hand means calling, nod of head means approving something, and many more. Indeed, semiotic turn into a way for producer to create the sign and the way for viewer to understand the sign.

In semiotics approach, there are two famous founders, namely Ferdinand de Saussure and Charles Sanders Peirce. Both of them were developing science of semiotic but they have different type and characteristic. In this study, the writer only focuses on one semiotic theory which sourced from Charles Sanders Pierce. However, the theory from Sausure will be described shortly as a comparison.

Saussure is the father of modern linguist from Europe. He built the s emiotic theory based on the language as the system of sign. Focusing on linguistics signs, such as words, Saussure asserts there are two sides of interpreting signs which called as signifier and signified. Signifier is the material aspect of thing, such as sound, letter, gesture, etc. While signified is the mental concept or the concept of thing (Sebeok, 2001). For example, when there is someone who says pen, the sound of how $/ \mathrm{p} / / \mathrm{e} / / \mathrm{n} /$ is heard is the signifier. Then, the concept of how a pen looks like is the signified. This process of interpreting a sign is called as semiology.

C.S. Pierce was known as the founder in the field of semiotic. He defines semiotics as study of sign. Pierce as cited in Chandler (2007) points out, "A sign is something which stands to somebody for something in some respect or capacity. It addresses somebody, that is, creates in the mind of that person an equivalent sign, or perhaps a more developed sign." In other word, the sign had substitute something for someone.

In addition, semiotic theory by Pierce focuses on meanings of the sign in broad sense which consist of three interconnected elements. Johansen (2002) holds: "The sign in narrow sense, also referred to as the representamen, that which represents something else; the object, that which the sign stands for, that which is represented by it; and finally the (possible or potential) meaning the sign allows for, which many materialize as its 
translation into a new sign. Peirce refers to this as the interpretant."

Based on some definitions above, it shows that the theory of semiotic by Pierce tries to investigate the problem of sign. The sign itself had substitute something for someone. To use Peirce's terminology, sign is divided into three elements. There are representament, object, and interpretant. Pierce gives explanation of representament as the sign itself; it can be words, phrases, sentences, sounds, and etc. The object is the thing which referred; it can be pictures, photographs, and etc. The interpretant is the product from the connection between representament and object; it can be image or concept. Taking the example from this explanation, the word pen is the representamen; yet the object is the pen physically; and the idea which is appeared when someone hears pen, such as pen has function to write on the paper as the interpretant.

The relationship between representament, object, and interpretant can be shown by the diagram as follows:

\section{Representament}

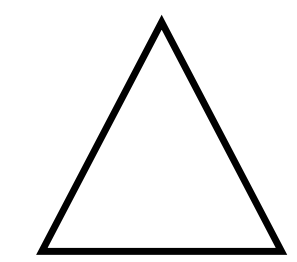

\section{Interpretant}

Object

Figure1. Triadic Semiosis Concept of Pierce (Sobur, 2006)

The schema above is called as triadic theory of Pierce. It describes unlimited semiosis. The representament will lead to object, then object to interpretant and interpretant to representament again. It is supported by Pierce's statement as cited in
Parmentier (1994) who states, "a sign, or representament is a First which stands in such a genuine triadic relation to a Second, called its Object, as to be capable of determining a Third, called its Interpretant, to assume the same triadic relation to its object in which it stands itself to the same Object." Through this relationship between Representamen + Object + Interpretant, it can deliver a clear meaning of selected object (advertisement) and use for communication.

\section{TYPOLOGY SIGNS CHARLES SANDERS PIERCE}

Peirce (1931-1935) distinguished the types of signs to be: Icon, Index, and Symbol based on the second trichotomy. 1) Icon: Icon is a sign which denotes and have the character of the Object, whether the Object actually exist or not. In the icon, the relationship between representament and object is materialized as similarities in some quality. For example, the map of DKI Jakarta is an icon of the DKI Jakarta area which depicted in the map. 2) Index: Index is the sign which is connected with the object because of the cause and effect connection. The example is a footprint above the ground. That is an index of a person or animal that has been passed there. 3) Symbol: Symbol is a general law or ideas which operates only in a particular situation, areas, or society. Symbol is also called as the type of sign which is arbitrary and conventional according to the agreement or convention of society. For example is the word of Bhineka Tunggal Ika. In Indonesia, this phrase has rich symbolic meaning. But for people who have different cultural background, such as Eskimos, the words Bhineka Tunggal Ika is only refers as ordinary phrases. 


\section{ADVERTISEMENT}

Advertisement has important role in marketing activities which offered into the public. It can influence costumers' mind and perception about the products, services, or ideas. It is supported by Arens (2004) who gives a definition for advertising. He says, "advertising is the structured and composed non-personal communication of information, usually paid for and persuasive in nature, about products, services, ideas by identified sponsors through various media." His statement means advertising is a paid form communication which has main function to promote products, services, and ideas. It attempts to persuade consumer to purchase or to consume more of particular brand of products or services. Generally, it reaches people through various media such as television, radio, or internet.

In advertisement, there are several components which can be a barometer to be categorized as a good advertisement that success to attract the consumers. Altstiel (2006) mention these components are visuals, colour, headline, subheads, taglines and body copy. Visuals advertising include elements such as photographs, illustrations and videos. Next, the use of colour in advertising has strong attention-attracting capabilities, particularly in magazines. Compared to blackand-white, advertising with colour is more interesting and attracting. Many female products are most suited for full-colour advertising such as cosmetics and accessories. Next, headline is the most read part of an advertisement. It is displayed in large type face than the rest texts. It usually presents a selling idea which intrigues prospects to further read the advertisement. Next, subhead is not always used in advertisement. However, when the advertiser wants to say a lot at the beginning but the headline cannot, then the subhead is used. It usually displayed below or before the headline. It is written in small type face than the headline but larger than the body text. Next, tagline or usually called slogan. It is a form of short and catchy word, phrase, or sentence which appears after logo to describe the benefit of the product. Next, body copy is a part which tell the story of advertisement. In the body copy, it provides supporting proof about quality, performance, and durability trough arguments, proof by experts, or testimonials by users.

Furthermore, Danesi (2004) divided the advertisement into three main categories, there are consumer advertising, trade advertising, and political-social advertising. Consumer advertising is directed towards the promotion of some products. Trade advertising is made to dealers and professionals through appropriate trade publications and media. Political-social advertising is used by politicians to advertise their platforms. However, this thesis uses consumer advertising because it correlates to the object of the research which is representation designed to promote the sale or marketable goods.

\section{RESEARCH METHOD}

In conducting this study, the descriptive qualitative approach has been chosen because the writer analyzed and described the semiotic on advertisement is in the form of essay. Bogdan (1992) states: "Qualitative research is descriptive. The data collected in the form of word or picture rather than number. They often contain quotation and try to describe what particular situation or vie of the world, like in narrative form. The written words are very important in the qualitative." 
The statement above can be assumed that qualitative research does not use the number or calculating analysis, statistical analysis and technical instruments but it is presented in the form of words or pictures which contains several quotations from expert. Creswell (2014) also highlighted "Qualitative methods rely on text and image data, and have unique steps in data analysis." It means that all the data which is in the form of text and image is suitable in qualitative method. On the other hand, qualitative method is not suitable to analyze the data in form of number.

\section{FINDING AND DISCUSSION}

Five selected smartphone advertisements of Oppo, such as Oppo smartphone F1, F5, N1 mini, R1, and R5 were analyzed. Those advertisements are gained from Oppo smartphone official website, www.oppo.com. All commercial advertisements of Oppo smartphone have creative design. The design of advertisement looks interesting by using signs. In order to get the meaning of each advertisement clearly, the signs are analyzed through semiotic approach from Pierce which focus on Representament, Object, and Interpretant. The semiosis process starts from the representament (R). The representament can be a picture or written language that used on the advertisement. After that, the semiosis process is continued to the next step by determining the object $(\mathrm{O})$. The object is the thing which referred. Then, the relationship between the representament and its object produces the interpretant (I). The interpretant is the writer's interpretation that produced by the combination of representamen and object.

\section{Semiosis Process of Picture 1}

(O)

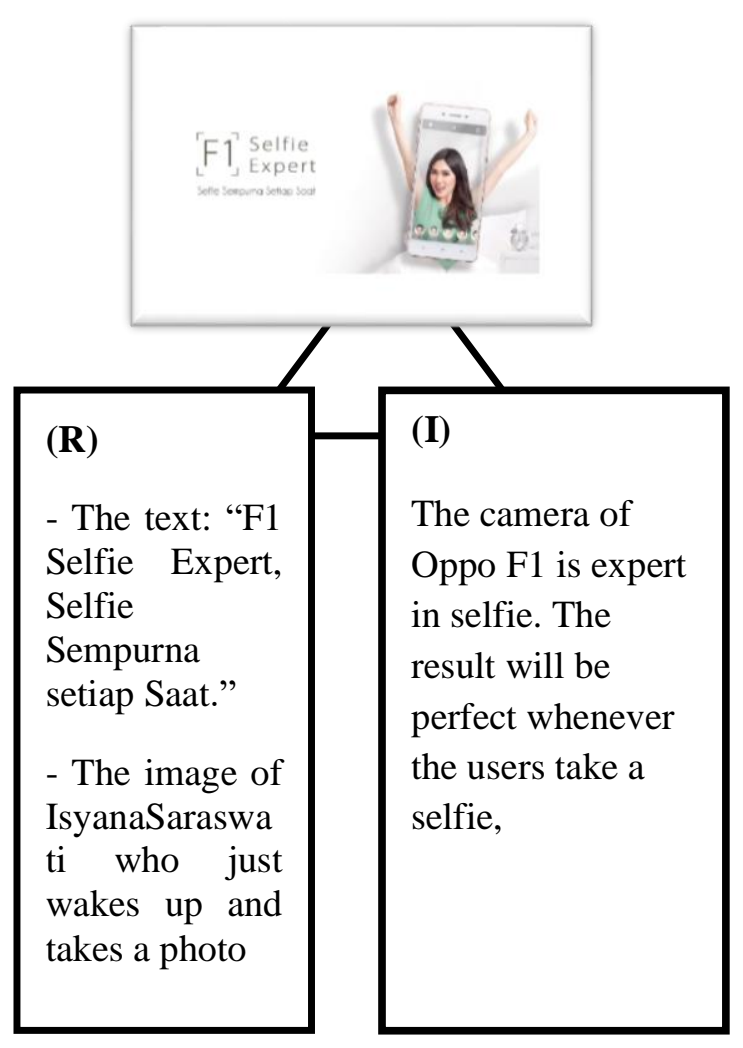

After analyzing the semiosis process above, the writer finds the message implied in the advertisement that the company wants to tell readers about the strength of Oppo F1. Oppo F1 has good camera phone that makes this smartphone as selfie expert. It is a good news for the users as selfie lovers because they can get perfect selfie anytime they want by using this smartphone device. Yet, when they just wake up in the morning, the users not to be worry anymore to take a selfie. They can still look perfect in the camera because Oppo F1 is supported with 16-Megapixel frontfacing camera and beauty feature that enables users to enhance their skin tone while taking selfie. Therefore, by using this advertisement, the company hopes the consumers who see the advertisement will be attracted to buy the 
product after knowing the strength of the product.

\section{Semiotic Process of Picture 2}

(O)

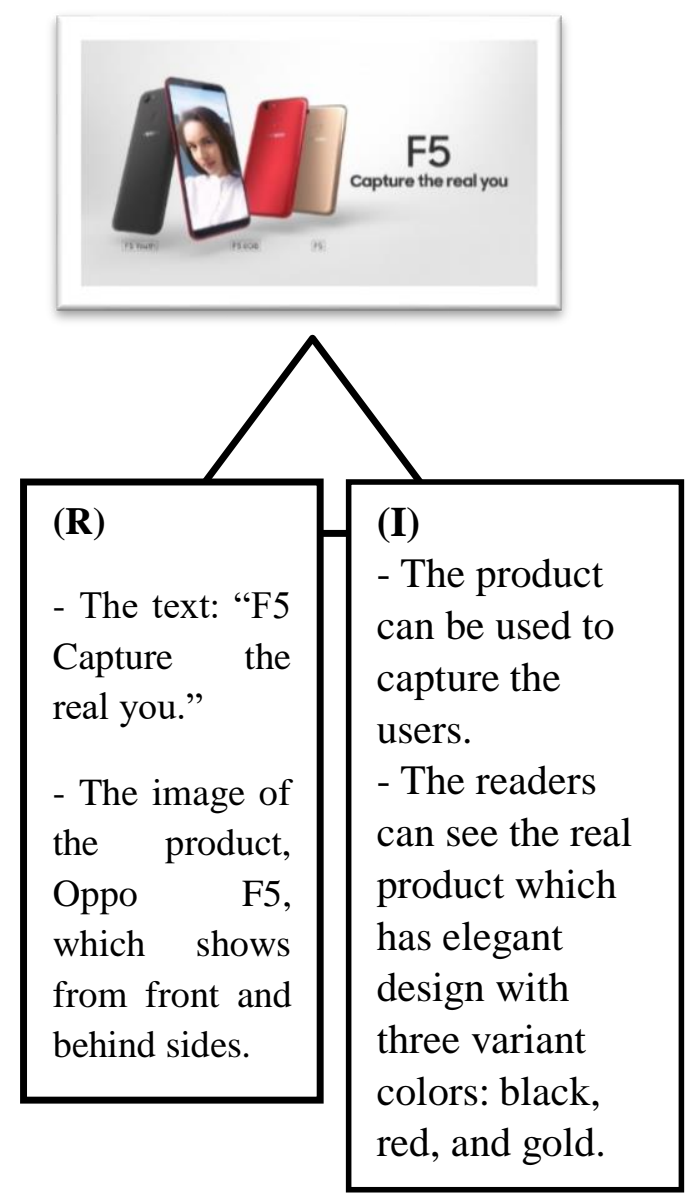

Through this advertisements, the writer finds the message that the advertiser wants to give the information for the readers about the function of this smartphone which can be used to capture the users. Nowadays, mobile phone is not only used as a communication tool between sender and receiver but also it can be used as a photography tool to capture something. People do not need complicated tool anymore like camera digital because Oppo F5 has a camera which is provided in the mobile phone. Besides, the advertiser also wants to inform readers about the design of Oppo F5.
It looks elegant with three variant colors; black, red, and gold.

\section{Semiotic Process of Picture 3}

(O)

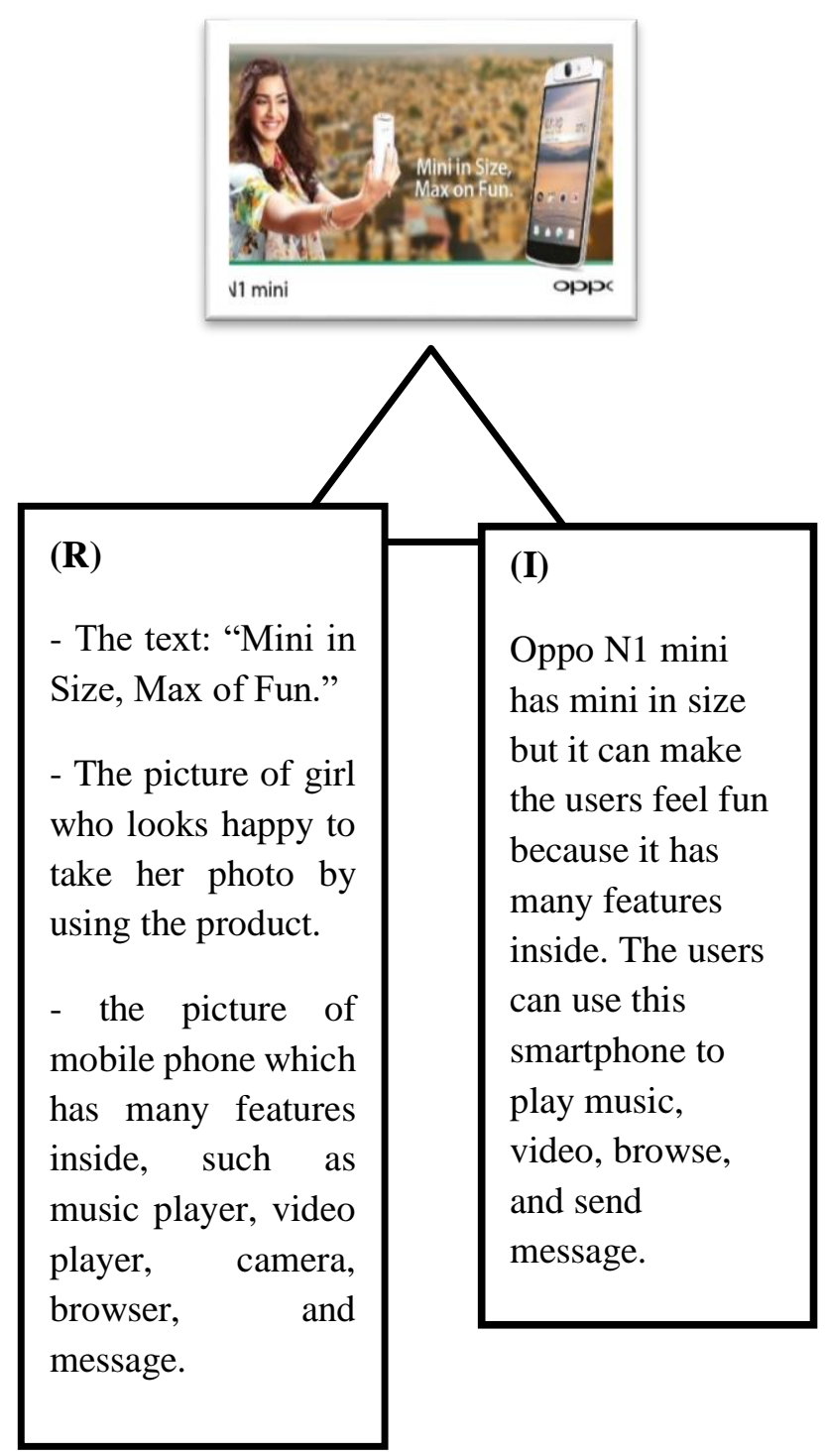

The message in the advertisement is the advertiser tries to inform the audience that Oppo N1 mini can make everyone who buys this smartphone feel happy. It is supported by the sentence which states, "Mini in Size, Max of Fun". Oppo N1 mini appears in small size and advanced features inside that make it fun to use. The features that provide in this smartphone can be seen by the picture of advertisement such as camera, music player, 
video player, browser, and message. It means, Oppo N1 mini can be used not only to communicate between sender and receiver but also these features inside can be used to take a photo, play favorite music and video, browse in the internet, and send a message.

\section{Semiotic Process of Picture 4}

(O)

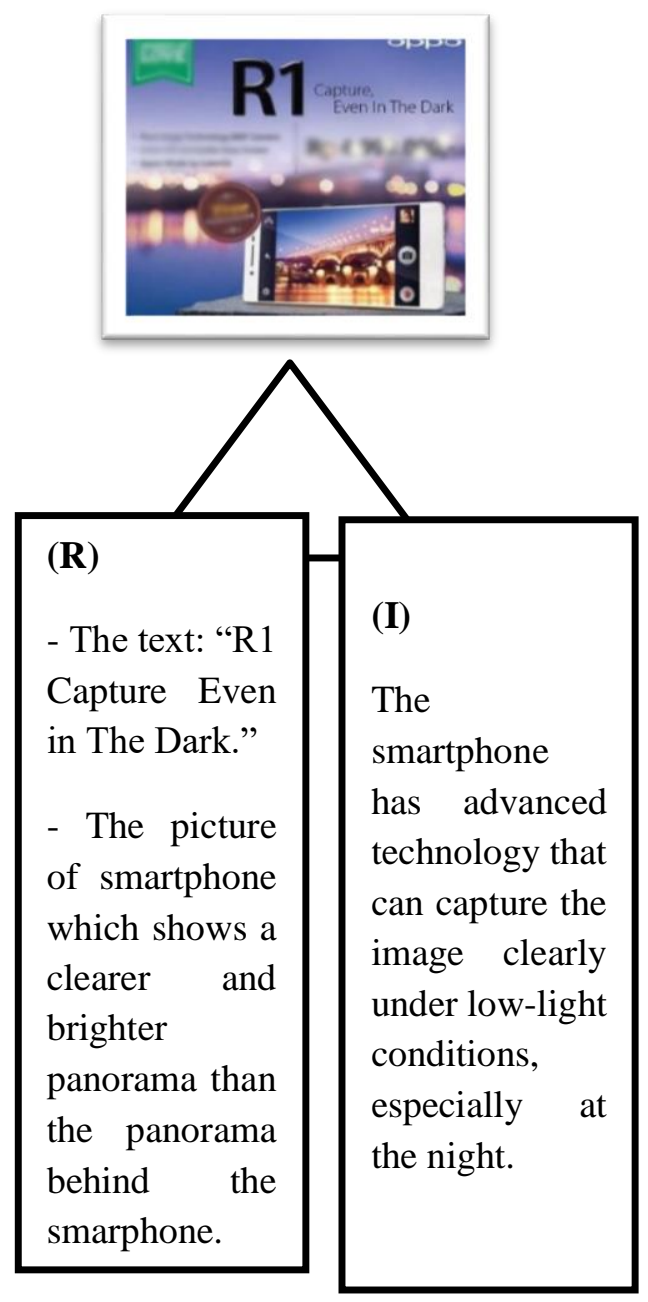

The message is found after analyzing this advertisement through semiotic approach from Pierce. By using this advertisement, Oppo company announces the readers that Oppo produces the latest smartphone device with advanced technology. The camera of Oppo R1 is really amazing because it can be used to capture the panorama in the dark.
Oppo R1 is equipped with 5MP front camera, 8MP rear camera uses a BSI CMOS sensor and an imx1179 coprocessor which makes this smartphone very good for selfie shots under low-light conditions, especially at the night.

\section{Semiotic Process of Picture 5}

(O)

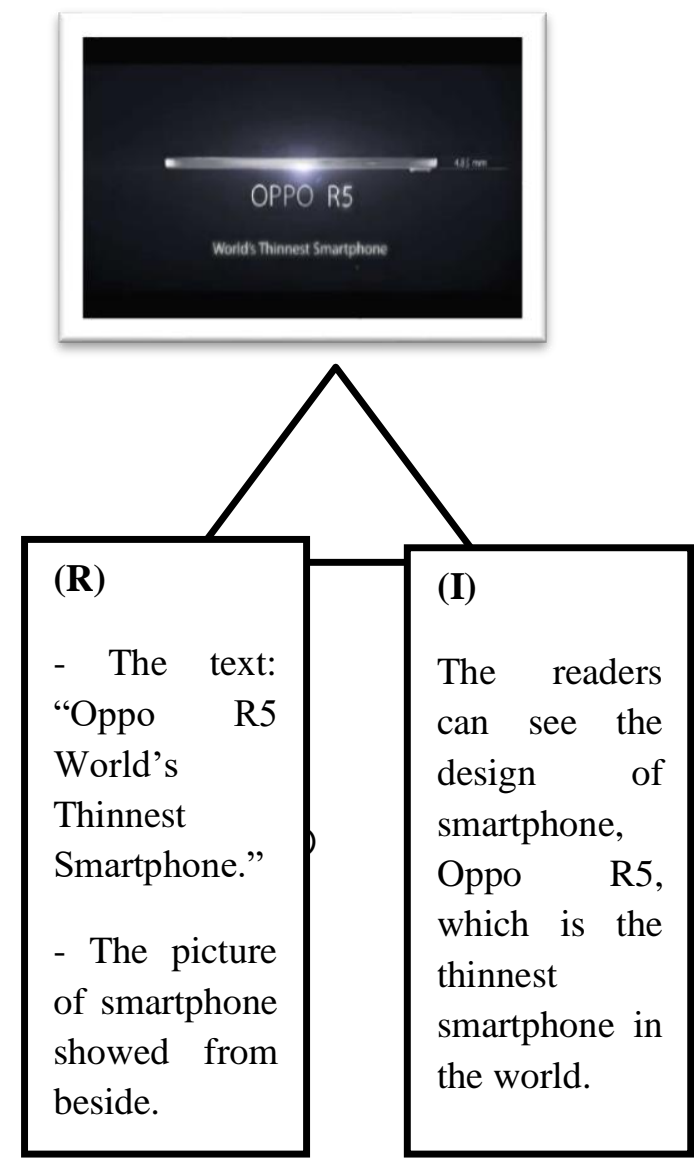

After analyzing the semiosis process above, the writer finds the message in this advertisement that the advertiser wants to give the information to the readers that Oppo R5 is a smartphone designed really thin. The readers can see how thin this smartphone by looking the advertisement which shows the picture of the product from beside. Oppo company declares that Oppo R5 is the thinnest smartphone in the world. The phone is just 4.85 millimeters thick with sharp curves and 
flat sides. It is agoodnews for the users who bored u sing smartphone with big size.

The writer classified all the commercial advertisements of Oppo smartphone above because the design of advertisement looks interesting by using signs. In order to get the meaning of each advertisement clearly, the signs were analyzed through triadic relation concept by Pierce's theory which starts from the reprsentament, the object, and the interpretant.

\section{CONCLUSION}

Based on the analysis that has been done, it can be concluded that Oppo smartphone is one of the famous smartphone brands that uses signs on its advertisement to attract people's attention to buy the product. The writer uses five selected Oppo smartphone advertisement as the object analysis. The advertisements are Oppo F1, F5, N1 mini, R1, and R5. Semiotic approach of Pierce was used in examining the signs of each advertisement of Oppo smartphone which is mostly constructed in the form of pictures with combining simple texts.

In analyzing these advertisements, the semiosis process starts from representament. The representament is the signs itself that can be a picture or a written language. After that, the semiosis process is continued to the next step by determining the object. The object is the thing which referred. Then, the relationship between the representament and its object produce the intepretant. The intepretant is the writer's interpretation that is produced by the combination of the representament and object.

The semiosis process above is used to uncover the hidden messages in five Oppo advertisements. Those advertisements have message implied about how good quality the product. Oppo F1 advertisement tries to inform the viewers that the camera is an expert in taking selfie. Oppo F5 advertisement tells the viewers that this product can be used to capture. Oppo N1 mini advertisement wants to give the information that the product can be used to take a photo, browse, play video, play music and send messages although the size is mini. Oppo R1 tries to inform the users that the product has advanced technology in camera which can be used to capture the panorama in the dark. Oppo R5 wants to tell the viewers that the design of this product is the thinnest in the world.

\section{REFERENCES}

Altsiel, G. (2006). Advertising Strategy: Creaive Tactic from Outside. UK: Sage Publication.

Arens, W. F. (2004). Cotemporary Advertising. New York: Mc-Graw Hill.

Bodgan, B., \& Taylor, S. J. (1998). Introduction to Qualitative Research Methods: Third Edition. New York: Wiley Inc.

Chandler, D. (2007). The Basic Semiotic. New York: Routledge.

Crewell, J. W. (2014). Research Design: qualitative, quantitative, and mixed methods approached. Fourth edition. Los Angeles:SAGE Publications, Inc.

Johansen, J. D., \& Larsen, S. E. (2002). Sign In Use: An Introduction to Semiotics. London: Routledge Taylor and Fracis Group.

Parmentier. R. (1994). Sign and Society. Bloomington: Indiana University Press

Sobur, A. (2006). Analysis Teks Media. Bandung: PT Remaja Rosda Karya. Sudjiman, P., \& Zoest, V. A. (1992). SerbaSerbiSemiotka. Jakarta: PT. Gramedia Pustaka Utama. 
Oppo F1 advertisement. Retrieved January

10, 2018, from http://www.cararoot. com/wp-content/uploads/2016/02/

Oppo-F1- selfie.jpg

Oppo F5 advertisement. Retrieved January 10, 2018,from https://static.rancahpost. co.id/wp.content/uploads/2017/11/Opp

o-F5-Indonesia.jpg

Oppo N1 mini advertisement. Retrieved January 10, 2018, from http://cdn.ndtv. com/tech/images/gadgets/oppo_n1_min i_india_launch.jpg

Oppo R1 advertisement. Retrieved January 10, 2018, from https://pbs.twimg.com/ media/BfEB71mCIAA5tCB.jpg

Oppo R5 advertisement. Retrieved January 10, 2018,from http://static.neow.in/ images/uploaded/2014/10/oppo-r5-

01.jpg 